\title{
When Is Diagnostic Subtraction Angiography Indicated Before Clipping of Unruptured and Ruptured Intracranial Aneurysms? An International Survey of Current Practice
}

\author{
Martina Sebök, Jean-Philippe Dufour, Marco Cenzato, \\ Yasuhiko Kaku, Michihiro Tanaka, Tetsuya Tsukahara, \\ Luca Regli, and Giuseppe Esposito
}

\section{Introduction}

Digital subtraction angiography (DSA) is considered the gold standard for understanding the angioanatomy in ruptured and unruptured intracranial aneurysms (IAs) [1-5]. More recently, computed tomography angiography (CTA) has been introduced as an alternative imaging modality for ruptured aneurysms [6]. Sensitivities ranging from 77-97\% and specificities ranging from $87-100 \%$ for the identification of ruptured aneurysms using CTA have been reported [3, 4, 7-9]. High-resolution magnetic resonance angiography (MRA), on the other hand, is frequently used for unruptured aneurysms as an alternative noninvasive modality [10]. In a systematic review [11] of studies evaluating the value of MRA for the diagnosis of intracranial aneurysms, a pooled sensitivity of $95 \%$ and pooled specificity of $89 \%$ have been reported. By comparison, in 2000 the very first meta-analysis

M. Sebök · J.-P. Dufour · L. Regli · G. Esposito $(\bowtie)$ Department of Neurosurgery, Clinical Neuroscience Center, University Hospital Zurich, University of Zurich, Zurich,

Switzerland

e-mail: Martina.Seboek@usz.ch; luca.regli@usz.ch; giuseppe.esposito@usz.ch

M. Cenzato

Department of Neurosurgery, Grande Ospedale Metropolitano

Niguarda, Milan, Italy

e-mail: marco.cenzato@ospedaleniguarda.it

Y. Kaku

Department of Neurosurgery, Asahi University Murakami

Memorial Hospital, Gifu, Japan

e-mail:kaku@murakami.asahi-u.ac.jp

M. Tanaka

Department of Neurosurgery, Kameda Medical Center,

Chiba, Japan

T. Tsukahara

Department of Neurosurgery, National Hospital Organization, Kyoto Medical Center, Kyoto, Japan
[12] reported a per-aneurysm pooled sensitivity and specificity of MRA of $87 \%$ and $95 \%$ for the detection of IAs, respectively. Both CTA and MRA can in many cases provide the necessary information for the preoperative planning of intracranial aneurysms, comparable to DSA [10, 11, 13, 14]. In cases of mural calcifications, CTA has a sensitivity superior to that of MRA [10, 15].

The goal of this survey is to investigate the daily practice regarding indications for DSA before clipping of ruptured and unruptured IAs in an international panel of neurovascular specialists.

\section{Methods}

\section{Survey Development and Distribution}

We elaborated an anonymous survey containing 23 multiplechoice questions (see Appendix) to investigate when and why cerebrovascular specialists consider a DSA to be indicated before the clipping of ruptured and unruptured IAs.

The survey was structured as follows. First, general questions about the responder's specialty and institution were asked: country, specialty of responder, number of treated aneurysms as main surgeon, and number of treated ruptured and unruptured aneurysms per year at responders' institution. Second, questions regarding the choice of aneurysm treatment and the quality of imaging modalities at the responders' institutions were asked. Third, responders were asked the situations (unruptured aneurysms/ruptured aneurysms/ruptured aneurysms with life-threatening hematoma) and aneurysm locations (MCA or locations other than MCA) in which microsurgical treatment is to be performed without preoperative DSA. Finally, responders were asked to select factors which in their view influence the need for preoperative 
DSA, from a list of aneurysm-, patient-, and treatmentrelated factors (Table 5).

A paper version of this survey was distributed to the attendees of the ninth European-Japanese Cerebrovascular Congress (EJCVC-www.ejcvc2018.com), which took place in Milan, Italy at 7-9 June 2018 and was thereafter collected. The EJCVC is a biennial cerebrovascular meeting initiated in Zurich in 2001 and represents a unique opportunity to gather the latest updates on neurovascular surgery and interventions for cerebrovascular diseases.

\section{Data Analysis}

Data were manually imported into a digital database (Statistical Package for the Social Science) (SPSS) version 24 for Windows (IBM, Armonk, New York, USA). The various results were reported as value or proportion (\%). Descriptive statistics were used to analyze the collected data. Categorical data were analyzed using the $\chi^{2}$ test. Statistical significance was defined at $p<0.05$.

\section{Results}

\section{Baseline Characteristics of Survey Responders}

The total number of participants at the EJCVC was 152. The survey was offered to all participants at the entrance to the conference auditorium. A total of 93 surveys were distributed and $67(72 \%)$ completed surveys were returned during the three days of the conference. The responders worked in 13 different countries. The baseline characteristics are shown in Table 1.

Eighty-five percent of all responders were neurosurgeons, $7.5 \%$ neurointerventionalists, and $7.5 \%$ hybrid neurosurgeons. A hybrid surgeon is a cerebrovascular specialist able to treat aneurysms both by microsurgical and by endovascular methods.

Seventeen percent of responders had treated more than 500 aneurysms as main surgeon, $18 \%$ between 200 and 500 aneurysms, $10 \%$ between 100 and 200 aneurysms, 23\% had treated between 20 and 100 aneurysms, and $12 \%$ between 1 and 20 aneurysms. Twenty percent of responders had never treated an aneurysm as a main surgeon.

Twenty-eight percent of all responders worked at institutions that treated 50-100 unruptured aneurysms per year, while $48 \%$ of all responders worked at institutions that treated 20-50 unruptured aneurysms per year.

Twenty-seven percent of all responders worked in institutions where the number of ruptured aneurysms treated per year is $50-100$, while $54 \%$ of responders worked at an institution treating 20-50 ruptured aneurysms per year.
Table 1 Baseline characteristics of 67 respondents to the survey Number of respondents (\%)

\begin{tabular}{|c|c|}
\hline \multirow{2}{*}{\multicolumn{2}{|c|}{ Continent }} \\
\hline & \\
\hline Europe & $50(75)$ \\
\hline Japan & $16(24)$ \\
\hline Other & $1(1)$ \\
\hline \multicolumn{2}{|l|}{ Specialty } \\
\hline Neurosurgeon & $57(85)$ \\
\hline Neurointerventionalist & $5(7.5)$ \\
\hline Hybrid surgeon & $5(7.5)$ \\
\hline \multicolumn{2}{|c|}{ Number of aneurysms treated as a main surgeon } \\
\hline None & $13(20)$ \\
\hline $1-20$ & $8(12)$ \\
\hline $20-100$ & $15(23)$ \\
\hline $100-200$ & $7(10)$ \\
\hline $200-500$ & $12(18)$ \\
\hline$>500$ & $11(17)$ \\
\hline \multicolumn{2}{|c|}{$\begin{array}{l}\text { Number of treated UNRUPTURED aneurysms at institution per } \\
\text { year }\end{array}$} \\
\hline$<20$ & $14(21)$ \\
\hline $20-50$ & $32(48)$ \\
\hline $50-100$ & $19(28)$ \\
\hline$>100$ & $2(3)$ \\
\hline \multicolumn{2}{|c|}{ Number of treated RUPTURED aneurysms at institution per year } \\
\hline$<20$ & $11(16)$ \\
\hline $20-50$ & $36(54)$ \\
\hline $50-100$ & $18(27)$ \\
\hline$>100$ & $2(3)$ \\
\hline \multicolumn{2}{|c|}{ Final decision for the type of treatment } \\
\hline Interdisciplinary & $53(80)$ \\
\hline Neurosurgeon & $10(15)$ \\
\hline Neurointerventionalist & $1(2)$ \\
\hline Hybrid surgeon & $2(3)$ \\
\hline
\end{tabular}

Concerning the final decision for the type of treatment, $80 \%$ of responders assume an interdisciplinary approach (on neurovascular boards or by directly discussing the cases among neurosurgeons, neuroradiologists, and neurologist).

Ninety-one percent of all responders worked at institutions offering good quality CTA and $97 \%$ at an institution with a good quality MRA (at least $1.5 \mathrm{~T}$ ). Good quality neuroimaging is defined as imaging capable of displaying every vessel of the circle of Willis in high definition. In cases where a preoperative DSA is considered indicated, $82 \%$ of responders also request tridimensional rotational sequences.

No statistical differences were seen in the baseline characteristics between survey responders from Europe and Japan.

\section{Impact of Aneurysm Location and Rupture Status}

For MCA aneurysms, $64 \%$ of survey responders would treat unruptured aneurysms without preoperative DSA, and 60\% 
Table 2 Crosstab of surgical aneurysm treatment without preoperative DSA based on aneurysm location - all survey responders

\begin{tabular}{l|l|l|l}
\hline & \multicolumn{3}{|l}{ Number of respondents (\%) } \\
\hline $\begin{array}{l}\text { Aneurysm } \\
\text { location }\end{array}$ & $\begin{array}{l}\text { Unruptured } \\
\text { aneurysm }\end{array}$ & $\begin{array}{l}\text { Ruptured } \\
\text { aneurysm }\end{array}$ & $\begin{array}{l}\text { In case of life } \\
\text { threatening } \\
\text { hematoma }\end{array}$ \\
\hline MCA & $43(64)$ & $40(60)$ & $65(97)$ \\
\hline $\begin{array}{l}\text { Other } \\
\text { location }\end{array}$ & $45(68)$ & $49(73)$ & $64(96)$ \\
\hline
\end{tabular}

of responders would treat ruptured MCA aneurysms without preoperative DSA. Ninety-seven percent of responders would treat ruptured MCA aneurysms with life-threatening hematoma without preoperative DSA (Table 2).

Regarding aneurysms in locations other than the MCA, $68 \%$ of survey responders would treat unruptured aneurysms without preoperative DSA, and $73 \%$ of responders would treat ruptured aneurysms without preoperative DSA. Ninety-six percent of all responders would treat ruptured aneurysms in other locations than the MCA with life-threatening hematoma without preoperative DSA (Tables 2 and 3). There were no statistically significant differences in decision-making regarding preoperative DSA for aneurysm treatments between European and Japanese neurosurgeons.

Because $20 \%$ of all responders never treated an aneurysm as a main surgeon, in Table 3 we adapted a crosstab of surgical aneurysm treatment without preoperative DSA based on aneurysm location and performed a calculation excluding survey responders who never treated an aneurysm as main surgeon. Results do not show significant changes if one does not consider the surgeons who never clipped an aneurysm (Tables 2 and 3).

\section{Impact of Surgeon Experience on Decision to Perform a Preoperative DSA}

The benchmark for an experienced surgeon was set at 100 treated aneurysms as main surgeon. Forty-five percent of survey responders classify as experienced aneurysm surgeons. Table 4 represents a crosstab of the impact of a surgeons' experience on the decision to perform a preoperative DSA. Because in cases of life-threatening hematoma nearly all survey responders decide to waive a preoperative DSA (Tables 2 and 3), the impact of experience in these cases was not calculated.

In cases of unruptured aneurysms in locations other than the MCA, experienced neurosurgeons treat aneurysms significantly more often without a preoperative DSA, compared to less experienced colleagues (experienced vs. lessexperienced: $80 \%$ vs. $43 \%, p=0.002$ ).

In cases of unruptured MCA aneurysms, a similar trend is seen: Experienced neurosurgeons perform surgeries without
Table 3 Crosstab of surgical aneurysm treatment without preoperative DSA based on aneurysm location-excluding survey responders who never treated an aneurysm as main surgeon

\begin{tabular}{l|l|l|l}
\hline & \multicolumn{3}{l}{ Number of respondents (\%) } \\
\hline $\begin{array}{l}\text { Aneurysm } \\
\text { location }\end{array}$ & $\begin{array}{l}\text { Unruptured } \\
\text { aneurysm }\end{array}$ & $\begin{array}{l}\text { Ruptured } \\
\text { aneurysm }\end{array}$ & $\begin{array}{l}\text { In case of life- } \\
\text { threatening } \\
\text { hematoma }\end{array}$ \\
\hline MCA & $37(70)$ & $36(68)$ & $51(96)$ \\
\hline $\begin{array}{l}\text { Other } \\
\text { location }\end{array}$ & $39(74)$ & $39(74)$ & $51(96)$ \\
\hline
\end{tabular}

Table 4 Impact of surgeon's experience to treat aneurysm without preoperative DSA

\begin{tabular}{|c|c|c|c|}
\hline \multirow[b]{2}{*}{ Aneurysm location } & \multicolumn{2}{|c|}{ Experienced surgeon $(n(\%))$} & \multirow[b]{2}{*}{$p$-value } \\
\hline & YES $(n=30)$ & $\mathrm{NO}(n=37)$ & \\
\hline \multicolumn{4}{|l|}{ MCA } \\
\hline Unruptured & $23(71)$ & $22(49)$ & 0.08 \\
\hline Ruptured & $24(80)$ & $25(68)$ & 0.20 \\
\hline \multicolumn{4}{|l|}{ Other location } \\
\hline Unruptured & $24(80)$ & $16(43)$ & 0.002 \\
\hline Ruptured & $22(73)$ & $19(51)$ & 0.18 \\
\hline
\end{tabular}

preoperative DSA more often than less experienced colleagues (experienced vs. less-experienced: $71 \%$ vs. $49 \%$, $p=0.08$ ).

For ruptured MCA aneurysms and ruptured aneurysms in other locations, the data again show differences in absolute numbers, whereby preoperative DSAs are less frequently requested by experienced neurosurgeons (but without reaching significant differences between the experienced and lessexperienced group).

\section{Factors Influencing the Decision to Perform a Preoperative DSA}

Table 5 summarizes aneurysm-related factors, patientrelated factors, and treatment-related factors that influence the choice of survey responders to perform a preoperative DSA.

The most important aneurysm-related factors indicating a preoperative DSA examination are: aneurysmal shape (fusiform or dissecting aneurysms: $>80 \%$ of responders ask for a preoperative DSA); infectious aneurysm etiology (72\% of responders); maximum aneurysm diameter $>25 \mathrm{~mm}$ (85\% of responders); paraclinoidal or posterior circulations aneurysms ( $>70 \%$ of responders); possible perforators and vessels arising from aneurysm sac (85\% of responders for both); intra-aneurysmal thrombus (73\% of responders); and previous treatment $(90 \%$ of survey responders).

There are no patient-related factors (age, clinical status) (Table 5) that influence the decision for a preoperative DSA. 
Table 5 Aneurysm-, patient- and treatment-related factors influencing the choice to perform a preoperative DSA

\begin{tabular}{|c|c|}
\hline & $\begin{array}{l}\text { Number of respondents } \\
\text { answering YES (\%) }\end{array}$ \\
\hline \multicolumn{2}{|l|}{ Aneurysm-related factors } \\
\hline \multicolumn{2}{|l|}{ Aneurysm location } \\
\hline $\begin{array}{l}\text { - Middle cerebral artery (MCA) proximal } \\
\text { (M1-M2 segments) }\end{array}$ & $29(43)$ \\
\hline $\begin{array}{l}\text { - Middle cerebral artery (MCA) distal } \\
\text { (M3-M4 segments) }\end{array}$ & $31(46)$ \\
\hline $\begin{array}{l}\text { - Carotid-posterior communicating artery } \\
\text { (PCom) }\end{array}$ & $35(52)$ \\
\hline - Carotid-anterior choroidal artery (ACho) & $41(61)$ \\
\hline - Carotid-T & $34(51)$ \\
\hline - Carotid-hypophyseal & $41(61)$ \\
\hline - Carotid-paraclinoidal (ophthalmic) & $48(72)$ \\
\hline $\begin{array}{l}\text { - Anterior cerebral artery (ACA) proximal } \\
\text { (A1-A2 segments) }\end{array}$ & $31(46)$ \\
\hline $\begin{array}{l}\text { - Anterior cerebral artery (ACA) proximal } \\
\text { (A3-A4 segments) }\end{array}$ & $29(43)$ \\
\hline \multicolumn{2}{|l|}{ - Anterior communicating artery (ACom) } \\
\hline - Anterior projecting & $31(46)$ \\
\hline - Posterior projecting & $39(58)$ \\
\hline - Superior projecting & $37(55)$ \\
\hline - Inferior projecting & $33(49)$ \\
\hline \multicolumn{2}{|l|}{ - Posterior circulation: } \\
\hline $\begin{array}{l}- \text { posterior inferior cerebellar artery } \\
\text { (PICA) }\end{array}$ & $47(70)$ \\
\hline $\begin{array}{l}\text { - others (anterior inferior cerebellar } \\
\text { artery, superior cerebellar artery, basilar } \\
\text { artery, posterior cerebral artery) }\end{array}$ & $51(76)$ \\
\hline \multicolumn{2}{|l|}{ Aneurysmal morphology } \\
\hline \multicolumn{2}{|l|}{ - Etiology: } \\
\hline - Saccular & $25(37)$ \\
\hline - Fusiform & $54(81)$ \\
\hline - Dissecting & $58(87)$ \\
\hline - Infectious (i.e., mycotic) & $48(72)$ \\
\hline \multicolumn{2}{|l|}{ - Shape: } \\
\hline $\begin{array}{l}\text { - Irregularity (bleb/lobulation/ } \\
\text { daughter aneurysm) }\end{array}$ & $40(60)$ \\
\hline - Broad neck & $41(61)$ \\
\hline \multicolumn{2}{|l|}{ - Maximum diameter (single): } \\
\hline$-<5 \mathrm{~mm}$ & $22(33)$ \\
\hline$->10 \mathrm{~mm}$ & $35(52)$ \\
\hline$->25 \mathrm{~mm}$ & $57(85)$ \\
\hline $\begin{array}{l}\text { - Possible perforators arising from the } \\
\text { aneurysm }\end{array}$ & $57(85)$ \\
\hline $\begin{array}{l}\text { - Efferent vessels arising from aneurysmal } \\
\text { sac }\end{array}$ & $57(85)$ \\
\hline $\begin{array}{l}\text { - Calcification/atherosclerotic plaque of the } \\
\text { aneurysm wall }\end{array}$ & $26(39)$ \\
\hline - Intra-aneurysmal thrombus & $49(73)$ \\
\hline - Recurrence/previous treatment & $60(90)$ \\
\hline $\begin{array}{l}\text { - Computational fluid dynamic analysis } \\
\text { based decision }\end{array}$ & $20(30)$ \\
\hline \multicolumn{2}{|l|}{ Patient-related factors } \\
\hline - Patient age: & \\
\hline
\end{tabular}

Table 5 (continued)

\begin{tabular}{c|l}
\hline & $\begin{array}{l}\text { Number of respondents } \\
\text { answering YES }(\%)\end{array}$ \\
\hline$-<40$ & $20(30)$ \\
\hline$-40-60$ & $18(27)$ \\
\hline$->60$ & $18(27)$ \\
\hline Clinical situation: & \\
\hline- SAH & $22(33)$ \\
\hline- Cranial nerve deficit & $23(34)$ \\
\hline- Clinical mass effect & $26(39)$ \\
\hline- Radiological mass effect & $23(34)$ \\
\hline- Previous SAH & $29(43)$ \\
\hline Treatment-related factors & \\
\hline Bypass contemplated & $52(78)$ \\
\hline $\begin{array}{c}\text { - Visualization of possible donor } \\
\text { artery (e.g. STA) }\end{array}$ & $51(76)$ \\
\hline- Visualization of possible recipient & $47(70)$ \\
artery & \\
\hline - Collateral circulation & $57(85)$ \\
\hline
\end{tabular}

Regarding treatment-related factors, $78 \%$ of responders would ask for a DSA preoperatively in cases where a flowreplacement bypass is contemplated as a treatment option. Similarly, $85 \%$ of responders would ask for a preoperative DSA to assess the collateral circulation in cases where the possibility of bypass is evaluated.

\section{Discussion}

The goal of the survey was to investigate, among an international panel of neurovascular specialists participating at the ninth EJCVC, the workup and in particular the indication for preoperative DSA for patients undergoing microsurgical treatment of ruptured or unruptured intracranial aneurysms.

The analysis of the survey showed that in more than $80 \%$ of responders, the final decision for the type of aneurysm treatment at the responder's institution is taken in an interdisciplinary setting.

Tables 2 and 3 show a crosstab of microsurgical aneurysm treatment without preoperative DSA based on aneurysm location and rupture status. For MCA aneurysms, approximately $60 \%$ of responders perform microsurgery without preoperative DSA, regardless of rupture status. For aneurysms in locations other than MCA, microsurgery is done without preoperative DSA in $68 \%$ of unruptured and $73 \%$ of ruptured cases. In the case of ruptured MCA and non-MCA aneurysms with life-threatening hematoma, the vast majority of the responders ( $96 \%$ and $97 \%$, respectively) perform surgery without preoperative DSA.

This high percentage of responders who do not perform a DSA in cases of life-threatening hematoma is to be expected. 
In these cases there is no time for a DSA examination: the hematoma must be evacuated and the brain decompressed.

For MCA aneurysms without life-threating hematoma, $40 \%$ of responders ask for a DSA preoperatively. This is quite a high percentage, especially if one considers the possible complications of a DSA: According to the literature, neurological complications after a DSA examination occur in $2.63 \%$ of cases, where $0.14 \%$ of these are strokes with permanent disability [16].

Our survey results suggest that a surgeons' experience plays a role in deciding whether a preoperative DSA is indicated. A clear difference between experienced ( $>100$ treated aneurysms as main surgeon) and less experienced neurosurgeons is seen especially in cases of unruptured aneurysms: experienced surgeons ask for a preoperative DSA significantly less frequently in these patients.

Regarding the difference in requests for a preoperative DSA in MCA aneurysms, an almost-significant difference is seen in unruptured aneurysms $(p=0.08)$ and a trend toward statistical significance is seen in ruptured aneurysms ( $p=0.20$ ) between experienced surgeons and less experienced surgeons.

To simplify our questionnaire and the statistical workup, we separated the aneurysm location into MCA and locations other than the MCA. As a consequence, the non-MCA group includes a heterogeneous group of aneurysms from the anterior and posterior circulation.

According to the consensus among neurovascular specialists, a preoperative DSA is performed more often for aneurysms of the posterior circulation. Our survey confirms this trend: $\geq 70 \%$ of survey responders perform a preoperative DSA in patients with posterior circulation aneurysms. Therefore, the higher percentage of survey responders performing surgeries without DSA in locations other than the MCA compared to MCA aneurysms regardless of rupture status (unruptured locations other than MCA vs. unruptured MCA aneurysms: $68 \%$ vs. 64\%; ruptured locations other than MCA vs. ruptured MCA aneurysms: $73 \%$ vs. $60 \%$ ) is a surprising finding.

Factors which in a high percentage of responders $(>70 \%)$ lead to the request for a preoperative DSA are: location of the aneurysm in the posterior circulation or paraclinoid aneurysms, non-saccular aneurysmal shape (fusiform or dissecting), infectious aneurysm etiology, maximum diameter of the aneurysm $>25 \mathrm{~mm}$, possible perforators or efferent vessels arising from the aneurysm sac, intra-aneurysmal thrombus, previous treatment of the aneurysm, bypass contemplated, and to assess the collateral circulation. All these factors could be considered as characteristics of complex aneurysms. This is an expected finding since a general consensus among the cerebrovascular specialists exists wherein any angioanatomical feature indicating the presence of a complex aneurysm should lead to a more detailed workup, including preoperative DSA. The aneurysmal complexity is namely related to at least one of the following features: (1) size $\geq 2.5 \mathrm{~cm}$, (2) anatomic location (vertebral, basilar, paraclinoid), (3) involvement of critical perforating or branch vessels, (4) previous treatment (endovascular or surgical), (5) dissecting, fusiform, saccular lesions with very broad neck, (6) intraluminal thrombosis, and (7) atherosclerotic plaques and calcifications of the aneurysm wall and/or neck [17-24]. There are no patient-related factors (except clinical status) that influence the decision for a preoperative DSA. This is an expected finding because in cases of bad clinical status, often caused by life-threatening hematoma, there is no time for a preoperative DSA.

One of the aims of the survey was to assess in which direction the use of diagnostic DSA before microsurgical management of ruptured and unruptured cerebral aneurysms is moving among European and Japanese neurosurgeons. Several advantages of both noninvasive CTA and invasive DSA are known and should be considered, as well as the possible complications of DSA. Previous studies introduced CTA as an alternative imaging modality for ruptured IAs and reported sensitivities ranging from 77-97\%, and specificities ranging from $87-100 \%[3,4,7,8]$. The most recent metaanalysis by Menke et al. [8] was published in 2011 and encompassed 45 previous studies, for a total of 3643 patients with ruptured and unruptured aneurysm. This meta-analysis reported an overall CTA sensitivity of $97.2 \%$ and a specificity of $97.9 \%$, as well as a per-aneurysm sensitivity of $95 \%$ and specificity of $96.2 \%$.

In a comparative analysis between CTA and DSA for the diagnosis of ruptured intracranial aneurysms, Philipp et al. [25] concluded that the accuracy of CTA for the diagnosis of ruptured intracranial aneurysm may be lower than previously reported: in fact they found a low sensitivity of CTA $(57.6 \%)$ for aneurysms smaller than $5 \mathrm{~mm}$ in size, located adjacent to bony structures, and for those arising from small caliber parent vessels.

The "Guidelines for the Management of Patients With Unruptured Intracranial Aneurysms" from the American Heart Association/American Stroke Association [9] recommend that due to its high sensitivity and specificity, even for smaller aneurysms, CTA can be considered as an initial diagnostic test for aneurysm detection and screening. However, the reconstruction methods may not accurately depict the true neck/dome/adjacent small vessel anatomy, but CTA is very useful in identifying mural calcification and thrombus, which can have a significant impact on treatment decisions $[15,26]$.

Several other advantages of CTA and MRA over DSA have been recognized, including reduced cost, avoidance of arterial injury and stroke, rapid acquisition, and retrospective manipulation of data. Furthermore, it is important to mention that both the radiation dosage and the volume of contrast 
media is inferior with CTA than DSA (one-third to one-half for a single CTA compared to a four-vessel DSA) $[10,15]$.

The most appropriate use of the above-mentioned imaging modalities, especially CTA and DSA, in guiding medical decision-making for treatment of ruptured and unruptured intracranial aneurysms, remains an issue of debate.

\section{Limitations}

Our survey has several limitations, particularly with regard to responder bias and generalizability. First, the survey was distributed to participants of the EJCVC 2018 and therefore the results represent the current European and Japanese practice but might not be generalizable to other regions. Second, responses were voluntary and could lead to a selection bias for people with a particular interest and/or knowledge in these issues. Finally, 20\% of all responders never treated an aneurysm as a main surgeon, indicating a possible limited experience in preoperative decision-making. Nonetheless, this subgroup of responders could have answered by using the decision-making algorithm of their working institution, which was the reason we included them in our analysis. However, we adapted a crosstab of surgical aneurysm treatment without preoperative DSA based on aneurysm location and performed a calculation excluding the responders who never treated an aneurysm as main surgeon. The results do not show significant changes if one does not consider the surgeons who never clipped an aneurysm (Tables 2 and 3).

\section{Conclusion}

There is still a high variability in the surgeons' preoperative decision-making regarding the indication for DSA before clipping of intracranial aneurysms, except in case of ruptured aneurysms with life-threatening hematoma, where most of the responders perform surgery without preoperative DSA. For MCA aneurysms, approximately $60 \%$ of responders perform microsurgery without preoperative DSA, regardless of rupture status. For aneurysms in locations other than MCA, microsurgery is done without preoperative DSA in $68 \%$ of unruptured and $73 \%$ of ruptured cases.

The factors favoring the execution of a DSA before clipping are related to the complexity of the aneurysm: aneurysmal shape (fusiform, dissecting), etiology (infectious), size ( $>25 \mathrm{~mm}$ ), possible presence of perforators or efferent vessels arising from the aneurysm, intra-aneurysmal thrombus, previous treatment, location (posterior circulation or paraclinoid), and flow-replacement bypass contemplated for final aneurysm treatment.
Moreover, a surgeons' experience plays a role in the decision-making regarding preoperative DSA, with experienced surgeons ( $>100$ aneurysms treated as main surgeon) requesting preoperative DSAs less frequently. This effect is especially pronounced in patients with unruptured aneurysms.

\section{Appendix: Survey Questions}

\section{In which country do you work?}

2. At which institution do you work? (if you want to answer)

\section{Which specialist are you?}
(a) neurosurgeon
(b) neurointerventionist (interventional neuroradiologist)
(c) hybrid surgeon
(d) neurologist
(e) neurointensivist (Neuro Intensive Care)
(f) other:

4. What is your position?
(a) chairman
(b) senior consultant (attending clinician)
(c) junior consultant (attending clinician)
(d) fellow
(e) resident
(f) other:

5. How many aneurysms have you treated in your career as main surgeon?
(a) none
(b) $1-20$
(c) $20-100$
(d) $100-200$
(e) $200-500$
(f) $>500$

6. How many patients with unruptured intracranial aneurysms are treated at your department per year?
(a) $<20$
(b) $20-50$
(c) $50-100$
(d) $>100$

7. How many patients with ruptured intracranial aneurysms are treated at your department per year?
(a) $<20$
(b) $<50$
(c) $50-100$
(d) $>100$ 
8. Who takes the final decision for the type of treatment?
(a) interdisciplinary (boards or discussion of the case among neurosurgeons, neuroradiologists, neurologists)
(b) neurosurgeon
(c) neurointerventionalist (interventional neuroradiologist)
(d) hybrid surgeon
(e) neurologist
(f) neurointensivist (Neuro Intensive Care)
(g) others:

9. Do you (or surgeons at your institution) nowadays treat surgically only aneurysms of the middle cerebral artery (MCA)?
(a) yes
(b) no
(c) I do not know

10. Have you (or surgeons at your institution) treated surgically in the past also intracranial aneurysms in other locations (i.e., not MCA aneurysms)?
(a) yes
(b) no
(c) I do not know

11. Does the neurosurgeon at your institution sometime decide by himself to treat a MCA aneurysm surgically without having involved the neurointerventionist in the decision-making?
(a) yes
(b) no
(c) I do not know

12. Does the neurosurgeon sometime decide by himself to treat an aneurysm in other locations (i.e., not MCA aneurysms) surgically without having involved the neurointerventionist in the decision-making?
(a) yes
(b) no
(c) I do not know

13. Does the neurointerventionist sometimes decide by himself to treat an aneurysm endovascular without having involved the neurosurgeon in the decision-making?
(a) yes
(b) no
(c) I do not know

14. Have you at your institution good quality Computed Tomography Angiography (CTA)?
(a) yes
(b) no

15. Have you at your institution good quality Magnetic Resonance Angiography (MRA) with at least 1.5 T or more?
(a) yes
(b) no

16. Do you treat surgically unruptured MCA aneurysms without preoperative Digital Subtraction Angiography (DSA)?
(a) yes
(b) no
(c) I do not clip
(d) I have not clipped yet

17. Do you treat surgically unruptured aneurysms in other locations (i.e., not MCA-aneurysms) without preoperative DSA?
(a) yes
(b) no
(c) I do not clip
(d) I have not clipped yet

18. Do you treat surgically ruptured MCA aneurysms without preoperative DSA?
(a) yes
(b) no
(c) I do not clip
(d) I have not clipped yet

19. Do you treat surgically ruptured aneurysms in other locations (i.e., not MCA-aneurysms) without preoperative DSA?
(a) yes
(b) no
(c) I do not clip
(d) I have not clipped yet

20. Do you operate ruptured MCA aneurysms without preoperative DSA in case of life-threatening hematoma?
(a) yes
(b) no
(c) I do not clip
(d) I have not clipped yet

21. Do you operate ruptured aneurysms in other locations (i.e., not MCA-aneurysms) without preoperative DSA in case of life-threatening hematoma?
(a) yes
(b) no
(c) I do not clip
(d) I have not clipped yet

22. By preoperative DSA, do you always ask for tridimensional rotational sequences?
(a) yes
(b) no
(c) I do not clip
(d) I have not clipped yet 
23. Which of the following criteria influence your choice to perform a preoperative DSA? If you do not know one or more answer, please do not cross the relative box.

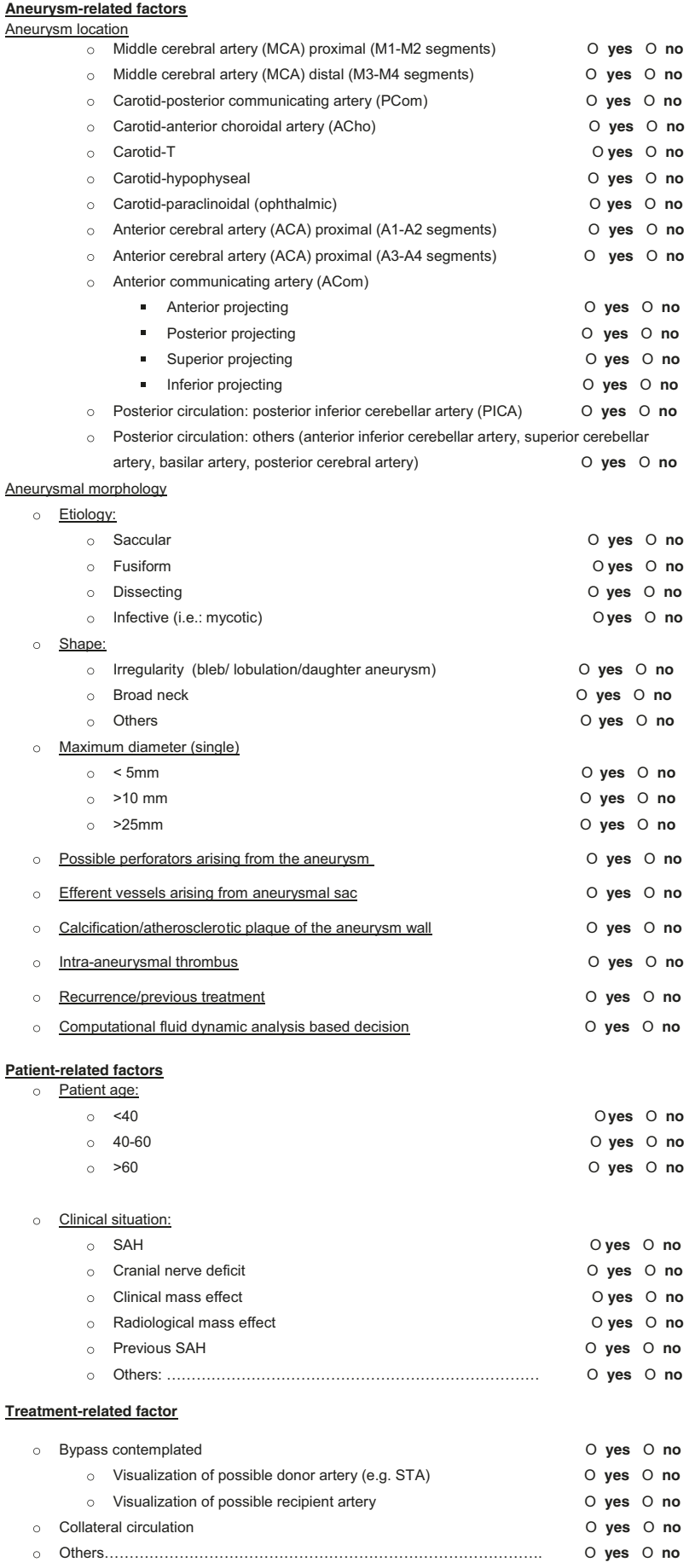

$O$ yes $O$ no $O$ yes $O$ no $O$ yes $O$ no Oyes $O$ no

$O$ yes $O$ no $O$ yes $O$ no

$O$ yes $O$ no

$O$ yes $O$ no

$O$ yes $O$ no

$O$ yes $O$ no

$O$ yes $O$ no

$O$ yes $O$ no

$O$ yes $O$ no

$O$ yes $O$ no

$O$ yes $O$ no

$O$ yes $O$ no

Oyes $O$ no $O$ yes $O$ no $O$ yes $O$ no

O yes $O$ no $O$ yes $O$ no $O$ yes $O$ no $O$ yes $O$ no $O$ yes $O$ no $O$ yes $O$ no

\section{References}

1. Brisman JL, Song JK, Newell DW (2006) Cerebral aneurysms. N Engl J Med 355:928-939. https://doi.org/10.1056/NEJMra052760

2. Marshall SA, Kathuria S, Nyquist P, Gandhi D (2010) Noninvasive imaging techniques in the diagnosis and management of aneurysmal subarachnoid hemorrhage. Neurosurg Clin N Am 21:305-323. https://doi.org/10.1016/j.nec.2009.10.005

3. Dammert S, Krings T, Moller-Hartmann W, Ueffing E, Hans FJ, Willmes K, Mull M, Thron A (2004) Detection of intracranial aneurysms with multislice CT: comparison with conventional angiography. Neuroradiology 46:427-434. https://doi.org/10.1007/ s00234-003-1155-1

4. Chappell ET, Moure FC, Good MC (2003) Comparison of computed tomographic angiography with digital subtraction angiography in the diagnosis of cerebral aneurysms: a meta-analysis. Neurosurgery 52:624-631; discussion 630-1.

5. Burkhardt JK, Chua MH, Winkler EA, Rutledge WC, Lawton MT (2019) Incidence, classification, and treatment of angiographically occult intracranial aneurysms found during microsurgical aneurysm clipping of known aneurysms. J Neurosurg 132:434-441. https://doi.org/10.3171/2018.11.Jns 182416

6. Dehdashti AR, Binaghi S, Uske A, Regli L (2006) Comparison of multislice computerized tomography angiography and digital subtraction angiography in the postoperative evaluation of patients with clipped aneurysms. J Neurosurg 104:395-403. https://doi. org/10.3171/jns.2006.104.3.395

7. Kangasniemi M, Makela T, Koskinen S, Porras M, Poussa K, Hernesniemi J (2004) Detection of intracranial aneurysms with two-dimensional and three-dimensional multislice helical computed tomographic angiography. Neurosurgery 54:336-340; discussion 340-1.

8. Menke J, Larsen J, Kallenberg K (2011) Diagnosing cerebral aneurysms by computed tomographic angiography: meta-analysis. Ann Neurol 69:646-654. https://doi.org/10.1002/ana.22270

9. Thompson BG, Brown RD Jr, Amin-Hanjani S, Broderick JP, Cockroft KM, Connolly ES Jr, Duckwiler GR, Harris CC, Howard VJ, Johnston SC, Meyers PM, Molyneux A, Ogilvy CS, Ringer AJ, Torner J (2015) Guidelines for the management of patients with unruptured intracranial aneurysms: a guideline for healthcare professionals from the American Heart Association/American Stroke Association. Stroke 46:2368-2400. https://doi.org/10.1161/ str.0000000000000070

10. Kouskouras C, Charitanti A, Giavroglou C, Foroglou N, Selviaridis P, Kontopoulos V, Dimitriadis AS (2004) Intracranial aneurysms: evaluation using CTA and MRA. Correlation with DSA and intraoperative findings. Neuroradiology 46:842-850. https://doi. org/10.1007/s00234-004-1259-2

11. Sailer AM, Wagemans BA, Nelemans PJ, de Graaf R, van Zwam WH (2014) Diagnosing intracranial aneurysms with MR angiography: systematic review and meta-analysis. Stroke 45:119-126. https://doi.org/10.1161/strokeaha.113.003133

12. White PM, Wardlaw JM, Easton V (2000) Can noninvasive imaging accurately depict intracranial aneurysms? A systematic review. Radiology 217:361-370. https://doi.org/10.1148/radiology.217.2.r 00nv06361

13. Joo SP, Kim TS (2017) The clinical importance of perforator preservation in intracranial aneurysm surgery: an overview with a review of the literature. Chonnam Med J 53:47-55. https://doi. org/10.4068/cmj.2017.53.1.47 
14. Stafa A, Leonardi M (2008) Role of neuroradiology in evaluating cerebral aneurysms. Interv Neuroradiol 14(Suppl 1):23-37. https:// doi.org/10.1177/15910199080140s106

15. Villablanca JP, Martin N, Jahan R, Gobin YP, Frazee J, Duckwiler G, Bentson J, Hardart M, Coiteiro D, Sayre J, Vinuela F (2000) Volume-rendered helical computerized tomography angiography in the detection and characterization of intracranial aneurysms. J Neurosurg 93:254-264. https://doi.org/10.3171/jns.2000.93.2.0254

16. Kaufmann TJ, Huston J III, Mandrekar JN, Schleck CD, Thielen KR, Kallmes DF (2007) Complications of diagnostic cerebral angiography: evaluation of 19,826 consecutive patients. Radiology 243:812-819. https://doi.org/10.1148/radiol.2433060536

17. Esposito G, Fierstra J, Regli L (2016) Distal outflow occlusion with bypass revascularization: last resort measure in managing complex MCA and PICA aneurysms. Acta Neurochir 158:1523-1531. https://doi.org/10.1007/s00701-016-2868-3

18. Esposito G, Dias SF, Burkhardt JK, Fierstra J, Serra C, Bozinov O, Regli L (2019) Selection strategy for optimal keyhole approaches for MCA aneurysms: lateral supraorbital versus minipterional craniotomy. World Neurosurg 122:e349. https://doi.org/10.1016/j. wneu.2018.09.238

19. Esposito G, Durand A, Van Doormaal T, Regli L (2012) Selectivetargeted extra-intracranial bypass surgery in complex middle cerebral artery aneurysms: correctly identifying the recipient artery using indocyanine green videoangiography. Neurosurgery 71:ons274ons284. https://doi.org/10.1227/NEU.0b013e3182684c45; discussion ons284-5.

20. Jafar JJ, Russell SM, Woo HH (2002) Treatment of giant intracranial aneurysms with saphenous vein extracranial-to-intracranial bypass grafting: indications, operative technique, and results in 29 patients. Neurosurgery 51:138-144; discussion 144-6.

21. Lawton MT, Hamilton MG, Morcos JJ, Spetzler RF (1996) Revascularization and aneurysm surgery: current techniques, indications, and outcome. Neurosurgery 38:83-92; discussion 92-4.

22. Esposito G, Regli L (2014) Surgical decision-making for managing complex intracranial aneurysms. Acta Neurochir Suppl 119:3-11. https://doi.org/10.1007/978-3-319-02411-0_1

23. Esposito G, Amin-Hanjani S, Regli L (2016) Role of and indications for bypass surgery after Carotid Occlusion Surgery Study (COSS)? Stroke 47:282-290. https://doi.org/10.1161/strokeaha.115.008220

24. Esposito G, Fierstra J, Regli L (2016) Partial trapping strategies for managing complex intracranial aneurysms. Acta Neurochir Suppl 123:73-75. https://doi.org/10.1007/978-3-319-29887-0_10

25. Philipp LR, McCracken DJ, McCracken CE, Halani SH, Lovasik BP, Salehani AA, Boulter JH, Cawley CM, Grossberg JA, Barrow DL, Pradilla G (2017) Comparison between CTA and digital subtraction angiography in the diagnosis of ruptured aneurysms. Neurosurgery 80:769-777. https://doi.org/10.1093/neuros/nyw113

26. Hirai T, Korogi Y, Ono K, Murata Y, Suginohara K, Omori T, Uemura S, Takahashi M (2001) Preoperative evaluation of intracranial aneurysms: usefulness of intraarterial 3D CT angiography and conventional angiography with a combined unit--initial experience. Radiology 220:499-505. https://doi.org/10.1148/radiology.220.2.r 01 au20499

Open Access This chapter is licensed under the terms of the Creative Commons Attribution 4.0 International License (http://creativecommons. org/licenses/by/4.0/), which permits use, sharing, adaptation, distribution and reproduction in any medium or format, as long as you give appropriate credit to the original author(s) and the source, provide a link to the Creative Commons license and indicate if changes were made.

The images or other third party material in this chapter are included in the chapter's Creative Commons license, unless indicated otherwise in a credit line to the material. If material is not included in the chapter's Creative Commons license and your intended use is not permitted by statutory regulation or exceeds the permitted use, you will need to obtain permission directly from the copyright holder. 